\title{
Tensiones entre lo social y lo personal en la construcción de la identidad docente
}

\author{
Tensions between the social and the personal in the construction of teaching identity
}

\section{Renatto Merino-Solari ${ }^{1}$}

"Si un yo no nos conduce a un nosotros, ese yo es estéril".

Alejandro Cussiánovich

\section{Resumen}

En el texto se explora el tema de la identidad docente. Propone comprender como las tensiones entre el contexto social y la dimensión personal configuran la identidad del docente. Se propone que es, precisamente, en esta compleja interacción que se (re) define su identidad. En esta ocasión recurrimos a una película peruana, Chicama, para explorar el tema. Asumimos el filme como una narración construida con elementos de la realidad que configuran un nuevo escenario para los hechos, por tanto, representa universos plausibles, historias posibles. En ese marco, explorar un filme es otra forma de conocer la realidad. Desde esta perspectiva realizaremos nuestra aproximación tanto a la película como al tema.

Palabras claves: identidad docente, imaginario social, experiencia personal, migración.

\section{Abstract}

The text explores the issue of teacher identity. It proposes to understand how the tensions between the social context and the personal dimension shape the identity of the teacher. It is proposed that it is precisely in this complex interaction that their identity is (re)defined. This time we appeal to a Peruvian movie, Chicama, to explore the subject. We assume the film as a narrative built with elements of reality that configure a new setting for facts, therefore, it represents plausible universes, possible stories. In this framework, exploring a film is another way of knowing reality. From this perspective we will make our approach to both the film and the subject.

Key words: teaching identity, social imagery, personal experience, migration.

\footnotetext{
Magíster en Antropología. Docente de la Facultad de Educación, Universidad Peruana Cayetano Heredia, Lima, Perú.
}

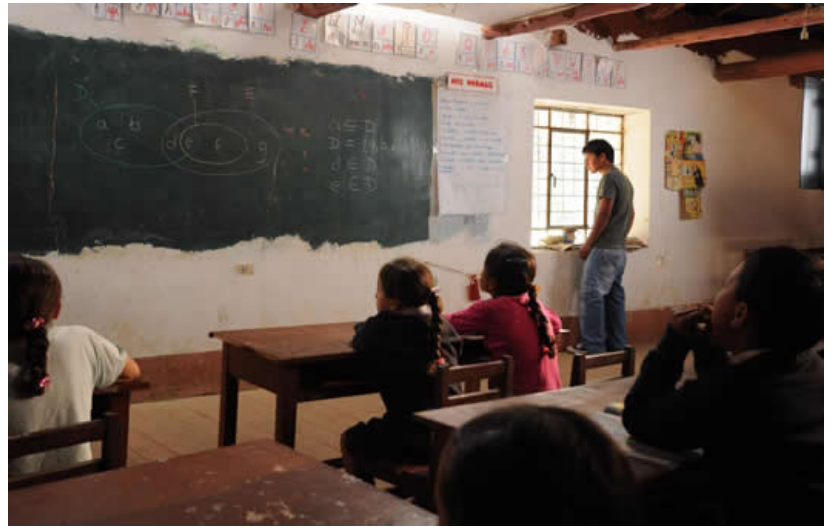

Chicama, película dirigida por Omar Forero, Perú 2012. Fuente: http: / / observandocine.com/ chicama/

\section{I}

La identidad profesional docente está relacionada con la pertenencia a sentirse parte de una comunidad laboral/profesional que se reconoce como tal y que, a su vez, es reconocida por los demás miembros de la sociedad: la colectividad de los docentes. Se trata de una identidad que se va formando, afirmando y definiendo desde la formación inicial del profesor, o incluso desde antes, y durante su trayectoria profesional. En este sentido, la identidad es una construcción que "requiere de un proceso individual 
y colectivo y es de naturaleza compleja y dinámica que se mantiene durante toda su vida laboral, lo que permite la configuración de representaciones subjetivas y colectivas acerca de la profesión docente". ${ }^{1}(1$, p. 31$)$

Por su parte, Galaz sostiene que un docente "posee tantas identidades o formas de definirse como sean los ámbitos de su socialización"; asimismo, "alude a la existencia de "identidades sustanciales y "situacionales" estableciendo un marco de diferencias en términos de duración, resistencia y posicionamiento". ${ }^{2}$ (2, pp. 91-92) Para el autor, existen elementos o contenidos de la identidad del docente que se caracterizan por su fuerza y significatividad; por ello, podemos entenderla mejor como "formando un núcleo caracterizado por su fuerte grado de transversalidad y por ser capaz de dotar de significado o sentido a aquellas identidades de carácter periférico". ${ }^{2}(2$, p. 92$)$

Para Argemí3 la identidad profesional docente se define en la intersección de las vertientes individual y colectiva. En la primera, el docente es entendido como un sujeto cultural con una vida y una trayectoria; en la segunda, es, a la vez, miembro de una sociedad y de un colectivo profesional que desenvuelve su labor profesional en una institución educativa.

Nos interesa resaltar que la identidad del docente se modela en las complejas interacciones generadas entre el contexto social/cultural y la dimensión personal. Al respecto, la experiencia relacional es básica, pues "la imagen de sí mismo se configura bajo el reconocimiento del otro". ${ }^{4}(4$ p.3) En los intercambios identitarios la mirada del otro es primordial, pues uno solo existe en la medida que es reconocido por otro; por tanto, la identidad del sujeto es, fundamentalmente, una experiencia compartida, una vivencia del nosotros.

Las transformaciones en la coyuntura política/ económica o la discontinuidad en los procesos, como las reformas educativas o las modificaciones en la legislación, genera momentos de cambio en los cuales los profesores (re)construyen su identidad; son situaciones en las que "los docentes organizan y reconfiguran sus interacciones, roles, prácticas y aprendizajes que hasta el momento venían sucediéndose". ${ }^{3}$ (3 p. 301)

Kaddouri y Vandroz, citados por Vanegas y Fuantealba, proponen como escenario de (re) definición para la identidad docente a los momentos de tensión:

"La identidad profesional docente pasa por tres tensiones: la primera, entre la confirmación de la identidad o vocación y la adquisición de una nueva identidad; la segunda, entre la identidad atribuida a la formación y la identidad reivindicada o comprobada; y la tercera, entre el proyecto identitario personal y el de los demás". 5 (5 p. 121)

Para los autores, las tensiones se presentan entre el ámbito personal y el desarrollo profesional laboral. Escenarios como la evaluación del desempeño docente, así como las condiciones laborales negativas afectan su labor, pero no al sentimiento de satisfacción profesional.3 La emergencia de nuevos roles, la diversidad de tareas con las que deben cumplir y los recursos limitados con los que cuentan también suelen poner en cuestión la identidad del docente..$^{4,6,7}$

El contexto educativo constituye un marco fundamental para el desarrollo de la identidad del docente. Así: "El entorno escolar, la naturaleza del contexto institucional o de los estudiantes, el impacto de los colegas y de los directivos escolares, influyen en la configuración de una identidad nueva". 5 (5 p. 122).

Desde otro ángulo:

"La construcción de la identidad docente es producto de un proceso dialéctico entre la identidad preexistente y el contexto, tanto a nivel educativo 
como a nivel subjetivo e intersubjetivo, que tiene como resultado un proceso de síntesis en el que se conjugan elementos personales y colectivos de su identidad Si la síntesis, producto de la contradicción entre el contexto educativo y la identidad docente es positiva, el docente puede permanecer vinculado laboralmente con el establecimiento, lo que conlleva a generar un sentido de pertenencia con el contexto...". .8 ( 8 . 137).

El contexto educativo, de manera particular la institución educativa, es un espacio generador de interacciones identitarias. La cultura docente es vivenciada intensamente al interior de la escuela, pues en ella anclan y cobran sentido los actores y elementos fundamentales del ejercicio docente. Consideramos que el proceso de síntesis que alcanza un maestro se resuelve, en gran medida, a partir de la institución educativa, especialmente desde el aula -microcosmos para las contradicciones de la sociedad y la cultura-.

Las relaciones que establece el profesor con los alumnos, con los padres de familia y entre colegas influyen significativamente en su identidad. El vínculo con los alumnos tiene un rol central en la constitución de esta identidad. Las evidencias muestran "que los maestros encuentran la mayor satisfacción en la actividad de enseñanza en sí misma y en el vínculo afectivo con los alumnos"9 (9 p. 9); asimismo, "Existe una tendencia marcada que ubica el logro de los objetivos previstos (de aprendizaje, de formación de los alumnos) como una de las experiencias más positivas de la profesión". 9 (9 p. 9).

En síntesis, los cambios socioeconómicos, culturales e ideológicos configuran factores que resultan imprescindibles para comprender los caminos que puede recorrer la identidad docente en nuestros tiempos. Dicho de otra manera, el contexto sociocultural influye significativamente en la formación y en la redefinición de la identidad profesional. Se trata de una dinámica interactiva entre lo social/cultural y lo personal que muchas veces es complementaria, pero en ocasiones es contradictoria. A partir de esos supuestos proponemos la siguiente pregunta: ¿Cómo la tensión entre el contexto social y la dimensión personal laboral reconfiguran la identidad docente? Asumiendo la identidad como una vivencia subjetiva intentamos comprender la forma en que las situaciones de tensión entre el contexto social y la experiencia personal cuestionan la identidad docente obligando al sujeto a una redefinición de su condición.

Para explorar el tema analizamos la película peruana Chicama de Omar Forero. Una película es una ficción, una invención, es decir, una narración construida con elementos de la realidad que configuran un nuevo escenario para los hechos. Entendemos la ficción en la línea de Geertz ${ }^{10}$, a saber, como "algo hecho", "algo formado", un "compuesto" y no necesariamente una cosa fingida o falsa. En este sentido el filme representa universos plausibles, historias posibles; hilvana discursos sociales con retazos de la realidad. El conocimiento también es una invención.11 En este marco, explorar una película es otra forma de conocer la realidad. Desde esta perspectiva realizaremos nuestra aproximación tanto a la película como al tema.

\section{II}

Chicama es una película peruana dirigida por Omar Forero. Entre los reconocimientos que ha obtenido destacan: Proyecto ganador del Concurso de Largometrajes Exclusivo para Regiones del País CONACINE 2010 del Ministerio de Cultura, Mejor Largometraje Peruano del 2012 por la Asociación Peruana de Prensa Cinematográfica (APRECI); además obtuvo 05 premios en el 16 Festival de Cine de Lima (2012), fue ganadora del premio a la Mejor Película Peruana del 2012 y ganadora del 
2do Concurso de Proyectos para Distribución de Obras Cinematográficas Peruanas de Largometraje, CONACINE 2012 del Ministerio de Cultura. ${ }^{12}$

Chicama fue filmada en Trujillo (distritos de Cascas y Huanchaco) y en Cajamarca (distrito de Santa Cruz de Toledo, provincia de Contumazá). Fue realizada con pocos recursos y dirigida con actores no profesionales. La propuesta de Forero consiste en reflejar los hechos por medio de una ficción que recrea una realidad, pero esta no se encuentra alejada de la que se vive cotidianamente. Nos presenta la vida tal como es y lo hace con un ritmo lento, minimalista. El director filma como si fuera un documental; en tal sentido, los actores no profesionales son funcionales a su propuesta, pues más que actuar se muestran tal como son. La película es discontinua, no pretende contar una historia de manera lineal, los acontecimientos van quedando inconclusos, sin resolución. En palabras del director: "la idea era que cada espectador concrete la historia en su cabeza". ${ }^{13}$

El argumento de Chicama gira en torno a César Castillo (José Sopán), un joven profesor que vive en el distrito de Cascas y espera con mucho entusiasmo iniciar su labor profesional en una Institución Educativa Pública (IEP) de Trujillo. Para César migrar a Trujillo es un ideal arraigado, pues forma parte del imaginario sociocultural de la población. Espera concretar su aspiración por medio de la plaza docente. Para ello presenta sus documentos a la Unidad de Gestión Educativa Local (UGEL). Luego de esperar pacientemente la asignación de la plaza, la representante de la UGEL le informa que no hay vacantes. La explicación de la funcionaria es que no tiene experiencia profesional y la competencia para acceder a una IEP en Trujillo es muy fuerte, pues se presentan profesores que llevan años en la carrera docente. A contracorriente de las aspiraciones de César, le ofrece un puesto como profesor en una escuela ubicada en la sierra de Cajamarca, en Santa Cruz de
Toledo: la IEP 80367. Inicialmente no acepta este ofrecimiento y decide seguir esperando la plaza anhelada. Mientras tanto, la mayoría de sus amigos, quienes también comparten el ideal de migrar a Trujillo, se van empleado en diferentes oficios que les permiten desplazarse hacia la "gran ciudad". Incluso, el "flaco" Pérez, también educador, logró ubicarse como profesor de un colegio privado en Trujillo, gracias a una tía, propietaria de la institución. Finalmente, y contrariando sus anhelos, César acepta la plaza para trabajar en la escuela de Santa Cruz de Toledo. Con muchas dudas emprende el viaje, al llegar al lugar es presentado a los niños y niñas por el director de la IEP. De esta manera, el joven profesor inicia su labor profesional, entre la insatisfacción por no estar en el lugar esperado y las expectativas que se van generando a partir del ejercicio profesional docente y las experiencias en el lugar.

La idea de migrar atraviesa el filme de principio a fin. En el pueblo de César los jóvenes migran, solo permanecen los mayores y los niños. No es un caso atípico en las provincias del Perú. "La situación está difícil", "me voy de todas maneras, aquí no hago nada" son expresiones comunes entre los pobladores de cualquier lugar del país. Mientras miraba el filme resulto inevitable recordar que mi padre también fue migrante, "norteño", llegó a Lima en 1940. En una ocasión, cuando estudiaba antropología, le pregunté: ¿Por qué dejaste tu tierra? $\mathrm{Su}$ respuesta fue concisa y precisa: "en Chiclayo cuando llegas a los 16 años no tienes nada que hacer". César y sus amigos, siete décadas después, experimentaban lo mismo.

Las migraciones del mundo rural al mundo urbano fueron el fenómeno social y cultural más trascendente del siglo XX. Los migrantes, al trasladar sus tradiciones y costumbres a las ciudades, delinearon el rostro moderno del Perú y forjaron la nueva identidad del país ${ }^{(14)}$. Migrar era sinónimo de modernidad y progreso: 
"Lo cierto es que al optar por sí mismos, por el futuro, por lo desconocido, por el riesgo, por el cambio, por el progreso, en definitiva, por partir, cientos de miles o millones de jóvenes comuneros, campesinos y provincianos en las últimas décadas se autodefinieron como "modernos", es decir, liberaron su subjetividad de las amarras de la tradición, del pasado, del suelo, de la sangre, de la servidumbre, convirtiéndose psicológicamente en "hombres libres". Y al hacerlo, sin ser conscientes de ello, cerraron una época del Perú para abrir otra". ${ }^{15}$ (15 p. 87)

Este es el imaginario que configura las expectativas sociales de César y en torno al cual se genera la primera situación que cuestiona su identidad docente. El joven profesor debe decidir entre el ideal de desplazarse a la urbe, con un futuro incierto respecto al ejercicio de su profesión, o trasladarse a un pueblo de la sierra para enseñar en una escuela rural. No es una decisión simple. La decisión, en gran medida, era una definición de su condición como sujeto y como profesional. Es importante recordar que la funcionaria de la UGEL le manifestó que las plazas para Trujillo eran difíciles porque se presentaban profesores con experiencia (pudo haber dicho que se presentaban los mejores); por el contrario, para la sierra sí tenía dos plazas para él (joven e inexperto). El discurso de la trabajadora de la UGEL subalterniza al sujeto en la medida que minusvalora sus competencias profesionales, y al contexto educativo rural, el cual es implícitamente definido como un espacio inferior, de menor importancia; es el lugar del no reconocimiento. El Perú, en diversos sectores, todavía reproduce la relación centro-periferia, relación asimétrica y de dominación, de la cual hablaban los teóricos de la dependencia el siglo pasado.

Es importante destacar que César está dispuesto a "salir adelante" por medio de su profesión. Confía en su carrera para alcanzar sus ideales. En este sentido, demuestra compromiso, evidencia vocación, algo que, podemos suponer, fue construyéndose entre la familia y el centro de estudios. Esta identificación también es utilitaria, pues para César el progreso está asociado al mundo urbano, a la vida en la ciudad. En este escenario, ser docente es un medio para salir del pueblo en busca de un futuro diferente.

Su empeño es valioso en la medida que la actividad docente no siempre remunera de la mejor manera y el camino por recorrer resulta incierto. El hecho que describe esto en la película es la decisión del "flaco" Pérez de abandonar la labor docente para convertirse en taxista, pues le permite lograr mejores ingresos económicos. Aquí, se presenta una realidad que vivencian los maestros del país: las bajas remuneraciones. Este es uno de los factores principales de insatisfacción profesional y ubica a la carrera docente como una de las actividades profesionales menos atractivas.

La segunda situación que confronta su identidad docente se origina en la relación con la profesora Juanita (Ana Paula Ganoza). Ella, joven y simpática, llega de Trujillo (Huanchaco). Está "saturada" de la vida en la ciudad. A diferencia de los demás, está muy interesada en conocer y compartir vivencias en el campo. Se maravilla con el paisaje y las características del lugar. Existe en ella una mirada exótica del mundo rural. El punto es que se presenta como una alteridad para César: ella viene del lugar al cual él desea ir. Le abre la posibilidad de otras miradas, así como nuevas expectativas. Para el espectador el filme parece decantarse hacia lo que pasará entre los jóvenes; sin embargo, se produce un giro en la historia cuando, en medio de una clase, la profesora debe abandonar el pueblo. Un caso más entre los profesores visitantes. Lo único que se supo es que debió regresar a Trujillo por problemas familiares. Y si bien es cierto, llegó una nueva profesora, el vínculo que se había generado con la profesora Juanita ya no era posible restablecerlo. César, en pleno proceso de arraigo y de afirmación profesional, parecía estar nuevamente descentrado. En esta situación, también sorpresivamente, decide viajar a Trujillo y encontrarse con sus amigos de 
Cascas. Para los niños y niñas del colegio un profesor más en la lista de los que se fueron y no regresaron: "todos los profesores que han venido se han ido... nadie se quiere quedar aquí", fue la contundente expresión de una de las niñas. Abandonar la institución educativa era una práctica sistemática que sumía a los niños y niñas en la pena y la resignación. El abandono, también puede ser una forma de violencia.

El contexto educativo se encuentra atravesado por el imaginario de la migración. Las expresiones del director del colegio cuando se dirige a los y las estudiantes son expresivas. En el discurso del director, los ejemplos a seguir para los niños y niñas de Santa Cruz de Toledo son las grandes personalidades que han estudiado en el colegio, pero que debieron irse (migrar) del pueblo para alcanzar el éxito. La escuela se encuentra desarraigada de la vida de la colectividad y de los saberes locales. Los conocimientos que imparten los profesores son datos que corresponden a realidades lejanas en el tiempo y el espacio. Los contenidos están descontextualizados, no son pertinentes culturalmente y no responden a la realidad socioeconómica del escenario. $\mathrm{Ni}$ la historia local, ni los saberes propios son incorporados en los contenidos, tampoco participan las personas representativas como autoridades o ancianos, más allá de la fiesta del pueblo. Asimismo, las sesiones de clase son repetitivas, memorísticas y tradicionales. La escuela es parte de la comunidad, pero funciona como un enclave: los profesores vienen del mundo de afuera, traen conocimientos de otras realidades y forman a los niños y niñas para que abandonen el lugar. El éxito está asociado a migrar, estudiar es el instrumento para lograrlo. Progresar implica dejar de ser y desarraigarse. En medio de este escenario, los profesores realizan su labor con dedicación, entusiasmo y cariño hacia sus estudiantes.

Luego de algunas experiencias con sus amigos en Trujillo, César decide regresar a la escuela. Las razones de esta decisión no quedan claras y el espectador debe concretar la historia. Entonces, podemos suponer que las relaciones establecidas en el contexto educativo, especialmente con los alumnos, tuvieron un rol preponderante en la decisión de retornar. César demuestra ser un maestro sensible, atento y preocupado por los niños y niñas. Entre ambos se construye un vínculo afectivo positivo, tierno, que influye favorablemente en la subjetividad (sentir/pensar/actuar) del profesor. Es evidente la identificación entre César y sus estudiantes, pues ambos comparten la inestabilidad, incertidumbre y falta de reconocimiento de una sociedad desigual. Así, el viaje le habría permitido reencontrar el sentido. En ocasiones, el Yo requiere desbordarse, negarse, para volver a Ser.

\section{III}

El objetivo del texto ha sido comprender la forma en que las tensiones entre lo social y lo personal (re) definen la identidad del docente. El tema se exploró por medio del análisis del filme Chicama de Omar Forero. César, el protagonista, es un profesor recién graduado que vivencia la tensión entre un imaginario social que modela su aspiración de migrar a Trujillo, en búsqueda de progreso y éxito, y su vocación profesional que debe concretar enseñando en una escuela rural. En este escenario se identificaron dos momentos de tensión vivenciados por el protagonista: i) la decisión de aceptar o no la plaza docente en la escuela rural y ii) el viaje a Trujillo abandonando su labor profesional. En el filme las situaciones se resuelven favorablemente: acepta la plaza y retorna al colegio. Por el marco social y cultural que encuadra las decisiones del joven profesor, la afirmación de su identidad docente fue, a la vez, una decisión política y una actitud ética.

$\mathrm{Su}$ identidad como profesor va construyéndose a partir de la interacción contradictoria entre las influencias del imaginario social y cultural predominante y su experiencia cotidiana en la institución educativa. Se trata de una interacción dinámica y compleja, en ocasiones armónica, en ocasiones friccional, que sitúa al maestro frente al 
reto de afirmar y reinterpretar permanentemente los fundamentos que dan soporte a su identidad profesional. En este sentido, resulta significativa la escena final de la película. El filme termina con los niños y niñas ingresando al aula, mientras el profesor los recibe en la puerta de entrada una niña le dice: "Profesor, ha faltado una semana". La puerta del salón es como el umbral que César debe recorrer en búsqueda de su identidad. Por ahora está de entrada, no sabemos si en el futuro nuevas tensiones lo hagan cruzar el umbral en otra dirección. El carácter dinámico y tensional de las construcciones identitarias deja abierta la posibilidad al cambio.

\section{Referencias bibliográficas}

1. Prieto M. La construcción de la identidad profesional del docente: Un desafío permanente. Revista Enfoques Educacionales. [Internet]. 2004 [acceso 10/2/2020]; 6(1):29-49. URL disponible en: https://enfoqueseducacionales.uchile.cl/index.php/REE/ article/view/48128/50756

2. Galaz A. El profesor y su identidad profesional ¿facilitadores u obstáculos del cambio educativo? Estudios Pedagógicos XXXVII. [Internet]. 2011[acceso 10/2/2020]; N.2:89-107. URL disponible en: https://scielo.conicyt.cl/scielo.php?script=sci arttext\&pid=S0718-07052011000200005

3. Argemí R. La identidad profesional docente: Concepto en constante (re)novación y (re)configuración. Estudio de caso en el Recinto educativo Llars Mundet (Barcelona).[Internet]. 2013 [acceso 8/2/2020]. URL disponible en: https://www. researchgate.net/publication/264166645_La_identidad_ profesional_docente_Concepto_en_constante_renovacion_y_ reconfiguracion_Estudio_de_caso_en_el_Recinto_educativo_ Llars Mundet Barcelona

4. Ramírez A. Carro A. La identidad profesional del docente de Educación Básica en el proceso de evaluación del desempeño. En: Congreso Nacional de Investigación Educativa-COMIE. San Luis Potosí. [Internet]. 2017 [acceso 8/2/2020]. URL disponible en: http://www.comie.org.mx/congreso/ memoriaelectronica/v14/doc/0626.pdf
5. Vanegas C. Fuantealba A. Identidad profesional docente, reflexión y práctica pedagógica: consideraciones claves para la formación de profesores. Perspectiva Educacional. Formación de profesores. [Internet]. 2019 [acceso 18/2/2020]; 58(1)115138. URL disponible en: https://scielo.conicyt.cl/scielo. php?script $=$ sci abstract\&pid $=$ S0718-97292019000100115\&lng $=$ es\&nrm $=$ iso

6. Tenti E. Consideraciones sociológicas sobre profesionalización docente. Educ Soc, Campinas. [Internet]. 2007 28(99):335-353. URL disponible en: http://www.scielo.br/pdf/es/v28n99/ a03v2899.pdf [acceso 22/1/2020]

7. Marcelo C. Formalidad e informalidad en el proceso de aprender a enseñar. Revista de Educación, 350. [Internet]. 2009 [acceso 20/2/2020]; 31-55. URL disponible en: http://www. revistaeducacion.educacion.es/re350/re350_02.pdf

8. Sánchez R. Cárdenas F. Contexto educativo: su relevancia en la construcción de la identidad docente. Revista Reflexión e Investigación Educacional. [Internet]. 2019 [acceso 15/3/2020]; vol 2, n.1 131-141. URL disponible en: http://revistas.ubiobio. cl/index.php/REINED/article/view/3870

9. Vaillant D. La identidad docente. En: I Congreso Internacional "Nuevas Tendencias en la Formación Permanente del Profesorado". Grupo de Trabajo sobre Desarrollo Profesional Docente en América Latina. Barcelona. [Internet]. 2007 [acceso 6/03/2020] URL disponible en: http://www.ub.edu/obipd/ docs/la_identidad_docente_vaillant_d.pdf

10. Geertz C. La interpretación de las culturas. Barcelona: Gedisa; 2000.

11. Foucault M. La verdad y las formas jurídicas. Barcelona: Gedisa; 1978.

12. Festival de cine de Lima PUCP [Internet]. Lima: PUCP; 2018 [acceso 20/10/2019]. URL disponible en: https://www. festivaldelima.com/2018/pelicula/chicama/

13. El placer de los ojos. Omar Forero [video]. 2014. [acceso 20/102019] [12:34 min.]. URL disponible en: https://www. youtube.com/user/elplacerdelosojos/videos

14. Matos Mar J. Desborde popular y crisis del Estado. Veinte años después. Lima: Fondo Editorial del Congreso del Perú; 2004.

15. Franco C. Imágenes de la sociedad peruana: la "otra" modernidad. Lima: Cedep; 1991.

\section{Correspondencia:}

Renatto Merino-Solari

renatto.merino.s@upch.pe

Fecha de recepción: 02-04-2020.

Fecha de aceptación: 11-01-20121.

Conflicto de interés: ninguno, según el autor.

Financiamiento: por el autor. 